\title{
RETURN OF TRAINING INVESTMENT (ROTI) TRAINING IN PTP NUSANTARA IV
}

\author{
Rohana Sinaga ${ }^{1)}$, Harmein Nasution ${ }^{2)}$, Nazaruddin Matondang ${ }^{3)}$ \\ rohanasin@yahoo.com, \\ ${ }^{2)}$ Dosen Departemen Teknik Industri Universitas Sumatera Utara \\ harmein_nst@yahoo.com \\ ${ }^{3)}$ Dosen Departemen Teknik Industri Universitas Sumatera Utara \\ nazaruddin_matondang@yahoo.com
}

\begin{abstract}
PT PTPN IV (PTPN IV) as one of the state-owned enterprises (SOEs) has made the transformation, including in terms of human resource management. This is reflected in a transformation program which has been launched by the Board of Directors PTPN IV, namely: human resources as the most important asset that must be transformed into a level of qualification that is recognized universally, in the aspects of competence, capability and integrity. To increase knowledge (knowledge), skills (skills) and attitude (attitude) to fit the demands of the post, periodically HR should be given education and training means that the education and training of human resources is an investment that can be interpreted by issuing a number of funds. Evaluation of training can be used as a measuring tool to help identify and analyze the training benefit significantly, demonstrating clear returns for the company, as the basis for evaluation of the training system during this time so that it can be improved in order to contribute to the training of the company. Significant changes occur on the competence of the ex-trainee aircraft operator on duty at the boiler palm oil mill PT PTPN IV, after they followed the training. This is evident from the average value of the competence of the former participants of the training changes are relatively high at 4.27 (good category) of the three domains of competence studied, the greatest changes occur is on the domain of skills of participants increased quality of the work with a score of 4,44 followed by Attitudes that increased motivation with a score of 4.40, respectively. Return on Training Investment (ROTI), obtained BREAD value of $420 \%$.
\end{abstract}

Keywords: Return on Training Investment (ROTI), training, education, evaluation.

\section{PENDAHULUAN}

Sumber daya manusia (SDM) merupakan salah satu aset yang senantiasa harus dipelihara dan ditingkatkan kemampuannya agar tujuan organisasi dapat terwujud. Untuk meningkatkan pengetahuan (knowledge), keterampilan (skill) dan sikap (attitude) agar sesuai dengan tuntutan jabatan, secara berkala SDM perlu diberikan pendidikan dan pelatihan. Pelatihan sebagai suatu upaya sistematis untuk meningkatkan pengetahuan (knowledge), keterampilan (skills) dan sikap kerja (behaviors) para karyawan melalui proses belajar (Noe, 2002). Dengan demikian dapat dinyatakan bahwa pendidikan dan pelatihan merupakan investasi SDM yang dapat diartikan dengan mengeluarkan sejumlah dana (sesuatu yang dapat diukur dengan uang) dalam meningkatkan pengetahuan, keterampilan kerja dan perilaku yang tujuan akhirnya untuk meningkatkan produktivitas 
kerja. PT Perkebunan Nusantara IV (PTPN IV) sebagai salah satu Badan Usaha Miliki Negara (BUMN) telah melakukan transformasi termasuk dalam hal pengelolaan SDM, dimana SDM sebagai salah satu asset yang paling penting yang harus ditransformasi menuju suatu tingkat kualifikasi yang diakui secara universal, dalam aspek kompetensi, kapabilitas dan integritas.

Dalam upaya meningkatkan kompetensi SDM, PTPN IV secara periodik melakukan pelatihan kepada karyawannya. Pada tahun 2013 biaya pelatihan yang dikeluarkan mencapai Rp 3.407.000.0000,- Biaya yang dikeluarkan untuk pelatihan tersebut sebaiknya perlu dilakukan evaluasi. Menurut Noe (2002), evaluasi pelatihan sebagai suatu proses pengumpulan keluaran yang dibutuhkan untuk menilai apakah sebuah program pelatihan sudah efektif atau belum sesuai dengan Surat Keputusan Kementerian Badan Usaha Milik Negara Nomor SK-16/S.MBU/2012 tentang Indikator/Parameter Penilaian dan Evaluasi atas Penerapan Tata Perusahaan Yang Baik (Good Corporate Governance) dan berdasarkan surat Nomor: S-153/S.MBU/2012, dimana setiap BUMN diharuskan melakukan penilaian dan evaluasi terhadap aktivitasnya termasuk dalam pelaksanaan kegiatan pelatihan yakni bagaimana persahaan mengevalusi efektivitas dan efisiensi sistem pembelajaran dan pengembangan. Mengacu kepada surat keputusan diatas maka perlu dilakukan penilaian terhadap efektifitas kegiatan pelatihan yang telah dilakukan secara terukur.

Umumnya, suatu pelatihan diselenggarakan dengan tujuan memberikan dampak yang positif terhadap kinerja perusahaan, misalnya peningkatan hasil penjualan, peningkatan hasil produksi, penurunan biaya produksi, peningkatan pelayanan nasabah, dan sebagainya (Tupamahu dan Soetjipto, 2005).

Beberapa peneliti menekankan pentingnya evaluasi pelatihan yang didasarkan pada perhitungan finansial agar mampu memberikan informasi yang nyata dan tegas kepada perusahaan mengenai kontribusi pelatihan tersebut terhadap kinerja perusahaan. Pagey (1981) menyatakan bahwa "sebagian besar organisasi dalam mengalokasikan jumlah anggaran untuk pelatihan sangat sedikit. Alasannya adalah bahwa pengembalian investasi pelatihan sangat sedikit. Jadi, banyak organisasi kurang berinvestasi pada pelatihan". Pagey (1991) telah mengembangkan pendekatan rasional secara kuantitatif untuk mengukur Return On Training Investment (ROTI), yang dikembangkan berdasarkan analisis biaya-manfaat. Semakin tinggi indeks ROTI, maka semakin efektif pelatihan yang telah dilakukan. 
PT Perkebunan IV (Persero), belum melakukan evaluasi sejauh mana hasil manfaat finansial yang didapat perusahaan dibandingkan dengan besarnya biaya yang telah dikeluarkan untuk kegiatan pelatihan, sehingga perlu dilakukan penelitian untuk mengetahui mengetahui besarnya return of training investment (ROTI) pelatihan. Penelitian ini bertujuan ntuk mengevaluasi pelatihan dengan ROTI agar diketahui seberapa besar manfaat finansial/ benefit dari kegiatan suatu pelatihan dan untuk merumuskan kebijakan pelatihan pada masa yang akan datang sehingga tujuan utama pelatihan dalam meningkatkan kompetensi SDM dapat terwujud.

\section{METODOLOGI}

Tahapan yang dilakukan untuk melakukan evaluasi pelatihan adalah sebagai berikut:

\subsection{Pengumpulan Data}

Data yang digunakan merupakan data yang dikumpulkan setelah program pelatihan dilakukan dan para eks-peserta pelatihan telah kembali ke tempat kerjanya semula, agar terdapat kesempatan yang cukup bagi mereka untuk menerapkan pengetahuan dan keterampilan yang diperolehnya selama pelatihan. Berdasarkan berbagai pertimbangan, pengumpulan data peserta dilakukan menggunakan kuesioner.

\subsection{Tahap Isolasi Pengaruh Pelatihan}

Kenyataan bahwa kegiatan pendidikan dan pelatihan akan memberikan dampak/pengaruh terhadap perubahan kinerja seseorang merupakan hal yang tidak terbantahkan. Pada penelitian ini untuk mengisolasi pengaruh pelatihan dari dari faktor lainnya menggunakan Langevin Learning Services (2001) yang meliputi faktor knowledge and skill, capacity, measurement, feedback, conditions, incentives. Setiap eks-peserta pelatihan diminta untuk memperkirakan/memberikan estimasi persentase dari setiap faktor tersebut terhadap perubahan atau peningkatan kinerja yang dialaminya setelah mengikuti pelatihan. Dalam penelitian perkiraan perubahan meliputi tiga kompetensi utama yaitu: pengetahuan (knowledge), keterampilan ( $(k i l l)$ dan sikap peserta (attitudes).

\subsection{Tahap Konversi Data Menjadi Monetary Values}

Mengkonversi data business results menjadi monetary values pada dasarnya merupakan tahap awal untuk mengekspresikan dampak pelatihan dalam ukuran finansial. Phillips (2002) membedakan business results dalam dua kategori data, yaitu hard data dan soft data. Pada penelitian ini digunakan hard data yaitu biaya operasi peasawat boiler. 


\subsection{Tahap Identifikasi Biaya Pelatihan}

Biaya pelatihan yang dikeluarkan untuk pelaksanaan suatu kegiatan pelatihan.

\section{HASIL DAN DISKUSI}

\subsection{Relevansi Pelatihan Dan Kompetensi}

Pada penelitian ini evaluasi pelatihan dilakukan terhadap 25 operator pesawat boiler yang tersebar di 14 pabrik kelapa sawit PTPN IV yang telah mengikuti pelatihan Operator Pesawat Uap Kls I (Boiler) yang dilakukan selama delapan hari, untuk selanjutnya ekspeserta pelatihan ini disebut dengan participant. Menurut Philips (2002), participant merupakan sumber data yang paling sering digunakan dan mereka berada pada posisi yang memungkinkan untuk memberikan data yang lengkap.

Untuk meningkatkan kompetensi operator pesawat uap boiler dilakukan pelatihan dengan tujuan yang ingin dicapai adalah sebagai berikut:

a. Mengetahui Keseimbangan Energi di Pabrik/PKS

b. Konsisten terhadap kapasitas Pabrik yang optimal

c. Mengetahui kebutuhan bahan bakar untuk pesawat Uap yang di operasikan

d. Mengetahui Efesiensi Boiler

e. Perubahan perilaku bekerja semakin baik

Hasil penelitian menunjukkan bahwa semua elemen pelatihan relevan dengan pekerjaan dengan nilai rata-rata 4,73, sebagaimana dapat dilihat pada Tabel 1.

Tabel 1. Relevansi Pelatihan

\begin{tabular}{|c|c|c|c|c|c|c|c|}
\hline \multirow{2}{*}{ No } & \multirow{2}{*}{ Elemen Program Pelatihan } & \multicolumn{5}{|c|}{ Distribusi jawaban } & \multirow{2}{*}{$\begin{array}{l}\text { Rata- } \\
\text { rata }\end{array}$} \\
\hline & & 1 & 2 & 3 & 4 & 5 & \\
\hline 1 & Materi pelatihan & $0 \%$ & $0 \%$ & $12 \%$ & $28 \%$ & $60 \%$ & 4,60 \\
\hline 2 & Diskusi kelas selama pelatihan & $0 \%$ & $0 \%$ & $8 \%$ & $28 \%$ & $64 \%$ & 4,76 \\
\hline 3 & Diskusi kelompok yang dilakukan selama pelatihan & $0 \%$ & $0 \%$ & $12 \%$ & $28 \%$ & $60 \%$ & 4,60 \\
\hline 4 & Role play yang dilakuakn selama pelatihan & $0 \%$ & $0 \%$ & $12 \%$ & $20 \%$ & $68 \%$ & 4,68 \\
\hline 5 & Praktek yang diberikan & $0 \%$ & $0 \%$ & $12 \%$ & $32 \%$ & $56 \%$ & 5.00 \\
\hline \multicolumn{7}{|c|}{ Rata-rata relevansi pelatihan dengan pekerjaan } & 4,73 \\
\hline
\end{tabular}

Keterangan : $1=$ sangat tidak relevan, $5=$ sangat relevan

Hasil wawancara dengan atasan participant menunjukan bahwa terjadi peningkatan komptensi operator yang telah dilatih dengan nilai rata-rata 4,27 yang merupakan katagori bagus. Hal yang menarik dari hasil penelitian ini adalah dari tiga domain kompetensi (knowledge, skills dan attitudes), ternyata yang paling besar perubahannya adalah dalam hal keterampilan (skills) peserta dengan skor 4,44, kemudian diikuti dengan peningkatan attitudes berupa peningkatan motivasi dan keinginan untuk berprestasi. Hasil penilaian dari atasan terhadap participant disajikan pada Tabel 2 
Tabel 2. Penilaian Atasan Terhadap Kinerja Eks-Peserta Pelatihan

\begin{tabular}{|c|c|c|c|c|c|c|c|}
\hline \multirow[b]{2}{*}{ No } & \multirow[b]{2}{*}{ Indikator Penilaian } & \multicolumn{5}{|c|}{ NILAI PESERTA (\%) } & \multirow[b]{2}{*}{$\begin{array}{l}\text { Rata- } \\
\text { Rata }\end{array}$} \\
\hline & & $\begin{array}{c}\text { Sangat } \\
\text { Kuran } \\
\text { g }\end{array}$ & $\begin{array}{c}\text { Kuran } \\
\mathbf{g}\end{array}$ & $\begin{array}{c}\text { Cuku } \\
\text { p }\end{array}$ & $\begin{array}{l}\text { Bagu } \\
\text { s }\end{array}$ & $\begin{array}{l}\text { Sangat } \\
\text { Bagus }\end{array}$ & \\
\hline 1 & $\begin{array}{l}\text { Laporan yang disampaikan peserta } \\
\text { setelah sampai di unit kerja }\end{array}$ & $0 \%$ & $0 \%$ & $16 \%$ & $80 \%$ & $4 \%$ & 3,88 \\
\hline 2 & $\begin{array}{l}\text { Kualitas dari tindak lanjut (action plan) } \\
\text { yang akan dilaksanakan }\end{array}$ & $0 \%$ & $0 \%$ & $4 \%$ & $76 \%$ & $20 \%$ & 4,16 \\
\hline 3 & $\begin{array}{l}\text { Motivasi dari peserta untuk melakukan } \\
\text { tindak lanjut }\end{array}$ & $0 \%$ & $0 \%$ & $12 \%$ & $36 \%$ & $52 \%$ & 4,40 \\
\hline 4 & $\begin{array}{l}\text { Perubahan sikap dan perilaku dalam } \\
\text { bekerja setelah kembali dari pelatihan }\end{array}$ & $0 \%$ & $0 \%$ & $4 \%$ & $64 \%$ & $32 \%$ & 4,28 \\
\hline 5 & $\begin{array}{l}\text { Kualitas hasil kerja setelah kembali dari } \\
\text { pelatihan }\end{array}$ & $0 \%$ & $0 \%$ & $0 \%$ & $56 \%$ & $44 \%$ & 4,44 \\
\hline 6 & $\begin{array}{l}\text { Kemauan peserta untuk membagi } \\
\text { pengetahuan dan keterampilan yang } \\
\text { diperoleh dari pelatihan }\end{array}$ & $0 \%$ & $0 \%$ & $4 \%$ & $60 \%$ & $36 \%$ & 4,32 \\
\hline 7 & $\begin{array}{l}\text { Peningkatan prestasi kinerja setelah } \\
\text { pelatihan }\end{array}$ & $0 \%$ & $0 \%$ & $0 \%$ & $60 \%$ & $40 \%$ & 4,40 \\
\hline \multicolumn{2}{|c|}{ Rata-rata } & & & & & & 4,27 \\
\hline
\end{tabular}

\subsection{Tahap Isolasi Pengaruh Pelatihan}

Setelah diketahui dampak perubahan perilaku pekerja, selanjutnya dilakuakn isolasi untuk mengetahui pengaruh sebenarnya kegiatan pelatihan. Untuk melakukan isolasi dilakukan dengan melihat sejauh mana pengaruh faktor eksternal yang meliputi kondisi ekonomi dan dukungan keluarga, serta pengaruh faktor internal yang meliputi dukungan atasan, rekan kerja, system bisnis proses, peralatan kerja, keterampuilan individu dan pelatihan yang diikuti. Dari hasil wawancara berdasarkan panduan yang telah dibuat didapat besarnya pengaruh pelatihan terhadap dampak kinerja participant sebesar 22,20\% sebagaimana dapat dilihat pada Gambar1.

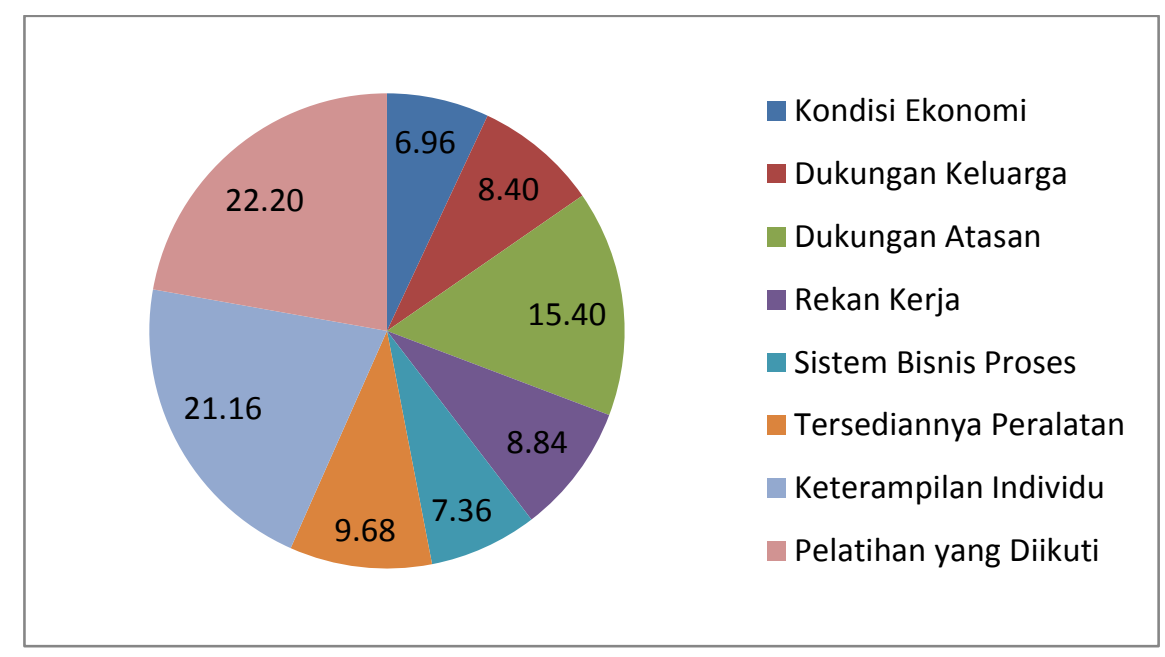

Gambar 5.1. Pengaruh Dampak Pelatihan 


\subsection{Tahap Konversi Data Menjadi Monetary Values}

\subsubsection{Perhitungan Benefit Pelatihan}

Setelah data diisolasi maka akan terlihat seberapa besar kontribusi pelatihan terhadap kinerja yang dilakukan oleh eks peserta pelatihan. Hasil pelatihan dapat dilihat pada Tabel 3.

Tabel 3. Penggunaan Bahan Bakar Boiler Sebelum dan Sesudah Pelatihan

\begin{tabular}{|c|c|c|c|c|c|c|}
\hline \multirow{2}{*}{ No. } & & \multirow{2}{*}{ Nama Responden } & \multirow{2}{*}{ Kebun } & \multicolumn{3}{|c|}{$\begin{array}{c}\text { Penggunaan Bahan Bakar Cangkang } \\
\text { (Kg/Jam) }\end{array}$} \\
\hline & & & & $\begin{array}{c}\text { Sesudah } \\
\text { Pelatihan }\end{array}$ & $\begin{array}{c}\text { Sebelum } \\
\text { pelatihan }\end{array}$ & Penghematan \\
\hline & 1 & SUPRIADI & & & & \\
\hline 1 & 2 & $\begin{array}{l}\text { ANTUS MARTUA } \\
\text { NASUTION }\end{array}$ & SOSA & 1.100 & 1300 & 200 \\
\hline 2 & $\begin{array}{l}3 \\
4\end{array}$ & $\begin{array}{l}\text { SAFARUDDIN } \\
\text { HASIBUAN } \\
\text { SUDARSO }\end{array}$ & BERANGIR & 1.215 & 1.350 & 135 \\
\hline 3 & 5 & ELISA LASE PASARIBU & PULU RAJA & 1.450 & 1.600 & 150 \\
\hline 4 & $\begin{array}{l}6 \\
7\end{array}$ & $\begin{array}{l}\text { AGUS PRATIKON } \\
\text { SUKARMIN SIAHAAN }\end{array}$ & AIR BATU & 1.200 & 1.400 & 200 \\
\hline 5 & 8 & EFFENDI MANURUNG & TINJOWAN & 1800 & 2000 & 200 \\
\hline 6 & $\begin{array}{l}9 \\
10\end{array}$ & $\begin{array}{l}\text { WARISMAN } \\
\text { E.SIMBOLON }\end{array}$ & ADOLINA & 1550 & 1.800 & 250 \\
\hline 7 & $\begin{array}{l}11 \\
12\end{array}$ & $\begin{array}{l}\text { R.PERANGIN ANGIN } \\
\text { ADENAN }\end{array}$ & $\begin{array}{l}\text { SAWIT } \\
\text { LANGKAT }\end{array}$ & 800 & 900 & 100 \\
\hline 8 & $\begin{array}{l}13 \\
14\end{array}$ & $\begin{array}{l}\text { SAMAN } \\
\text { SUTRISNO II }\end{array}$ & $\begin{array}{l}\text { GUNUNG } \\
\text { BAYU }\end{array}$ & 1900 & 2100 & 200 \\
\hline 9 & $\begin{array}{l}15 \\
16\end{array}$ & $\begin{array}{l}\text { SUYADI } \\
\text { HADI SUTRISNO }\end{array}$ & MAYANG & 1300 & 1500 & 200 \\
\hline 10 & $\begin{array}{l}17 \\
18\end{array}$ & $\begin{array}{l}\text { SYAHFRUDDIN } \\
\text { M.MP.SIRINGO-RINGO }\end{array}$ & $\begin{array}{c}\text { PASIR } \\
\text { MANDOGE }\end{array}$ & 1700 & 1900 & 200 \\
\hline 11 & $\begin{array}{l}19 \\
20\end{array}$ & $\begin{array}{l}\text { SADIO } \\
\text { PONIRIN }\end{array}$ & $\begin{array}{l}\text { DOLOK } \\
\text { SINUMBAH }\end{array}$ & 1800 & 2.000 & 200 \\
\hline 12 & $\begin{array}{l}21 \\
22\end{array}$ & $\begin{array}{l}\text { MESRIADI } \\
\text { PONIRIN.II }\end{array}$ & DOLOK ILIR & 1850 & 2000 & 150 \\
\hline 13 & $\begin{array}{l}23 \\
24\end{array}$ & $\begin{array}{l}\text { HISBULLAH } \\
\text { RUSLI }\end{array}$ & PABATU & 1600 & 1.800 & 200 \\
\hline 14 & 25 & RUKIJO & BAH JAMBI & 1800 & 2.000 & 200 \\
\hline & & JUMLAH & & 21.065 & 27.436 & 2.585 \\
\hline
\end{tabular}

Berdasarkan Tabel 3, terlihat bahwa terjadi kenaikan kinerja operator di dalam mengoperasikan boiler, dimana terjadi efektifitas penggunaan bahan bakar cangkang perhari sebesar $2.585 \mathrm{Kg}$. Dengan memperhitungakan jam operasi kebun per hari antara 20 sampai 22 hari kerja dan harga bahan bakar cangkang sebesar Rp. 500,- per Kg, serta dampak pelaksanaan pelatihan antara 10 sampai dengan 50\% didapat besarnya benefit untuk seluruh pabrik PKS milik PT Perkebunan Nusantara IV per tahun adalah Rp. $661.500 .000,-$

\subsubsection{Perhitungan Biaya Pelatihan}


Biaya pelatihan dihitung dengan mempertimbangkan komponen-komponen kegiatan pelatihan. Untuk pelatihan Operator Pesawat Uap Kls I (Boiler) diperlukan total biaya sebesar Rp. 157.367.256,- dimana rinciannya disajikan pada Tabel 4.

Tabel 4. Biaya Pelatihan Operator Pesawat Boiler

\begin{tabular}{clr}
\hline No. & \multicolumn{1}{c}{ Jenis Biaya } & Jumlah (Rp.) \\
\hline 1 & Perencanaan dan Pengembangan & 14.000 .000 \\
2 & Biaya Training dalam paket, pengajar,hand out, sertifikat, training kit, & 110.584 .000 \\
& konsumsi, dokumentasi,foto copy, peralatan dan Fasilitas lainnya & \\
3 & Biaya Transfortasi peserta dan Panitia & 13.000 .000 \\
4 & Gaji peserta (selama 8 hari ) mengikuti pelatihan & 10.721 .336 \\
5 & Uang Perjalanan Dinas Peserta & 9.061 .920 \\
& Total Biaya Pelaksanaan Pelatihan & 157.367 .256 \\
\hline
\end{tabular}

\subsubsection{Perhitungan Return On Training Investment}

Perhitungan Return on Training Investment (ROTI) dilakukan dengan menggunakan formula sebagai berikut:

$$
\text { ROTI }=\frac{\text { Net Benefits of Training }}{\text { Costs of Training }} \times 100 \%
$$

dimana Net Benefits of Training merupakan keuntungan bersih yang diperoleh dari hasil penerapan pelatihan setelah memperhitungkan faktor isolasi yang telah diperhitungkan pada tahap sebelumnya dikurangi dengan realisasi biaya pelatihanyang dikeluarkan. Berdasarkan hasil perhitungan manfaat dan biaya pelatihan sebagaimana disajikan pada Tabel 6.3 dan 6.4, besarnya ROTI dapat dihitung sebagai berikut:

$$
\begin{array}{ll}
\text { Manfaat pelatihan } & =\text { Rp. 3.102.000.000,- } \\
\text { Biaya pelatihan } & =\text { Rp. } 157.367 .256,- \\
\text { Manfaat bersih pelatihan } & =\text { Rp. 661.500.000,- } \\
\text { ROTI }=\frac{661.500 .000}{157.367 .256} \times 100 \%=420 \%
\end{array}
$$

\subsection{Perubahan Kompetensi Dan Implementasi Pelatihan}

Penelitian yang dilakukan menunjukkan umumnya eks-peserta pelatihan berpendapat bahwa pelatihan operator pesawat boiler memiliki relevansi yang kuat dengan pekerjaannya sehari-hari. Penelitian yang dilakukan menunjukkan bahwa semua elemen pelatihan memiliki rata-rata nilai mencapai 4,27 pada skala penilaian $1,00-5,00$ atau dengan kata lain bahwa kegiatan pelatihan telah berhasil meningkatkan kompetensi peserta relatif meningkat. Selain relevan, pelatihan operator pesawat boiler juga memiliki kontribusi yang cukup signifikan. Peserta pelatihan menyatakan bahwa umumnya tujuan pelatihan telah tercapai dengan adanya peningkatan pengetahuan dan kemampuan eks- 
peserta dikaitkan dengan pekerjaan sehari-hari yang dihadapinya. Besarnya pengaruh pelatihan terhadap peningkatan kemampuan peserta mencapai $22,20 \%$.

\subsection{Dampak Training Terhadap Kinerja Pegawai}

Sesuai dengan tujuan penyelenggaraannya, maka fokus utama dampak pelatihan operator pesawat boiler terhadap kinerja pegawai adalah dalam hal meningkatkan kemampuan peserta dalam melakukan proses pengoperasian pesawat boiler. Sebagaimana diketahui bahwa dalam mengoperasikan boiler, biaya yang paling besar adalah penggunaan bahan bakar cangkang. Dari hasil penelitian ditemukan bahwa, pelatihan operator pesawat boiler telah berhasil melakukan penghematan penggunaan bahan bakar yang besarnya mencapai Rp. 661.500.000,- per tahunnya.

\section{KESIMPULAN}

Berdasarkan analisis dan pembahasan yang dilakukan, dapat ditarik beberapa kesimpulan sebagai berikut: Terjadi perubahan yang cukup signifikan setelah mereka mengikuti training tersebut. Hal ini terlihat dari nilai rata-rata perubahan kompetensi eks peserta training relatif tinggi, yaitu 4,27 ( kategori bagus ) Dari ketiga domain kompetensi yang diteliti, maka perubahan yang paling besar terjadi adalah pada domain skill peserta meningkatnya kualitas hsil kerja dengan skor 4,44 diikuti dengan Attitudes yaitu peningkatan motivasi dengan skor masing masing sebesar 4,40. Terjadi peningkatan kinerja eks-peserta pelatihan operator pesawat boiler berupa peningkatan efisiensi penggunaan bahan bakar boiler dengan besarnya penghematan mencapai Rp. 661.500.000,- per tahunnya. Return on Training Investment (ROTI), diperoleh nilai ROTI sebesar $420 \%$. Nilai tersebut menunjukkan bahwa manfaat yang diberikan oleh pelatihan operator pesawat boiler jauh lebih besar dari pada biaya yang dikeluarkan untuk penyelenggaraan pelatihan operator pesawat boiler tersebut. Dengan demikian, pada akhirnya dapat disimpulkan bahwa pelatihan operator pesawat boiler cukup berharga untuk diselenggarakan di kemudian hari.

Salah satu kelemahan dalam ilustrasi ini adalah bahwa evaluasi training hanya dilakukan terhadap eks-peserta training saja. Meskipun hal tersebut masih dapat dipertanggung jawabkan secara ilmiah, namun tidak dapat dipungkiri bahwa evaluasi yang dilakukan secara $360^{\circ}$ akan memberikan hasil yang lebih baik dan obyektif. dilakukan wawancara untuk memperkuat hasil yang diperoleh. Penghitungan sejenis berikutnya dapat dilakukan terhadap jenis-jenis training yang tidak terkait dengan operasi perusahaan 
ataupun core-business secara langsung. Training dimaksud dapat terkait dengan peningkatan kompetensi yang bersifat soft-skills, seperti training mengenai kepemimpinan (leadership) atau kerjasama (teamwork), maupun kompetensi yang bersifat hard-skills namun termasuk kegiatan penunjang bisnis (support activities), seperti training tentang akuntansi atau audit.

\section{DAFTAR PUSTAKA}

Almeida, Rita (2008).The Return to Firm Investments in Human Capital. SP Discussion Paper No. 0822. Social Protection \& Labor, The World Bank.

Anonymus (2005). 5 Creative ways to Measure Training Return on Invesment.IOMA'S Report on Managing Training \& Develovment, 3,1-3

Barker, Kathryn. (2002). Why Train? Calculating the Return on Training Investment. Open Learning Agency. Burnaby.

Bartel, Ann P. (2000). Measuring the Employer's Return on Investments in Training: Evidence from Literature. Industrial Relations, Vol 39, No. 3 (july 2000).

Burns,Alvin C.and Bush, R.F.(2000).Marketing Research $3^{\text {rd }}$ ed.Englewood Cliff, New Jersey: Prentice-Hall

Burrow,Jim\&Berarnidelli,Paula (2003). Systematic Performance Improvement -Refining the Space Between Learning and Result. Journal of Workplace Learning , 15, 6-13

Carr,Wendy F." Designing an Efective Training Evaluation Process", SHRM White Paper,December 1999.

Cyrs, Thomas E ( 1998). Evaluating Distance Learning Program and Courses.Educational Develovment Associates, 3, 1-2

Farrel, Don G.(2005).What The ROI of Training Programs? Lodging Hospitality,61,46.

Fitz-enz,jac.(2000).ROI of Human Capital.New York: AMACOM, American Management Association.

Goldstein,Irwin (1993). "Training in Organizations : Needs Assesment,Development, and Evaluation. $3^{\text {rd }}$ ed.California:Brooks/cole/Publishing Company.

Gordon,Edward E" Training ROI" , Answering the Return on Invesment Puzle", SHRM White Paper,August 1999.

Kirpatrick,Donald L, and Kirpatrick,J,D.(2006).Evaluating Training Programs.San Fransisico: Berret -Koehler.

Lilly, Frances." Four Steps to Computing Training ROI" , SHRM White Paper,February 2001.

Lynch,Kara.,Akridge, Jay T.,Schaffer, Scott P. and Gray, Allan. (2006). A Framework for Evaluating Return on Investment inManagement Development Programs1. International Food and Agribusiness Management Review. Volume 9, Issue 2, 2006

Noe,Raymond A.(2002).Employe Training and Development. $2^{\text {nd }}$ ed. New York: McGraw-Hill

Philips,Jack J.(1997).Return on Invesment in Training and Performance Improvement Programs.Houston : Gulf Publishing company.

Sudjana (2008), (http://teknologikinerja.wordpress.com/2008/07/23training-evaluationmodel-part-1/)

Tupamahu, Stefan dan Soetjipto, Budi W. (2005). Pengukuran Return on Training Investment (ROTI). Lembaga Management, Fakultas Ekonomi Universitas Indonesia. 